\title{
4D Printing via an Unconventional Fused Deposition Modeling Route to High-Performance Thermosets
}

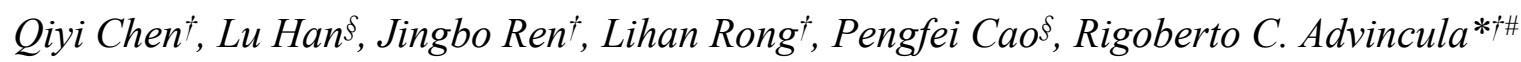

[*] Prof. R. C. Advincula (rca41@ case.edu)

${ }^{\dagger}$ Department of Macromolecular Science and Engineering, Case Western Reserve University, Cleveland, Ohio 44106, USA

$\S$ Chemical Sciences Division, Oak Ridge National Laboratory, Oak Ridge, Tennessee 37830, USA

\#University of Tennessee, Department of Chemical and Biomolecular Engineering, Knoxville, Tennessee 37996 and Center for Nanophase Materials Sciences, Oak Ridge National Laboratory, Oak Ridge, Tennessee 37830, USA

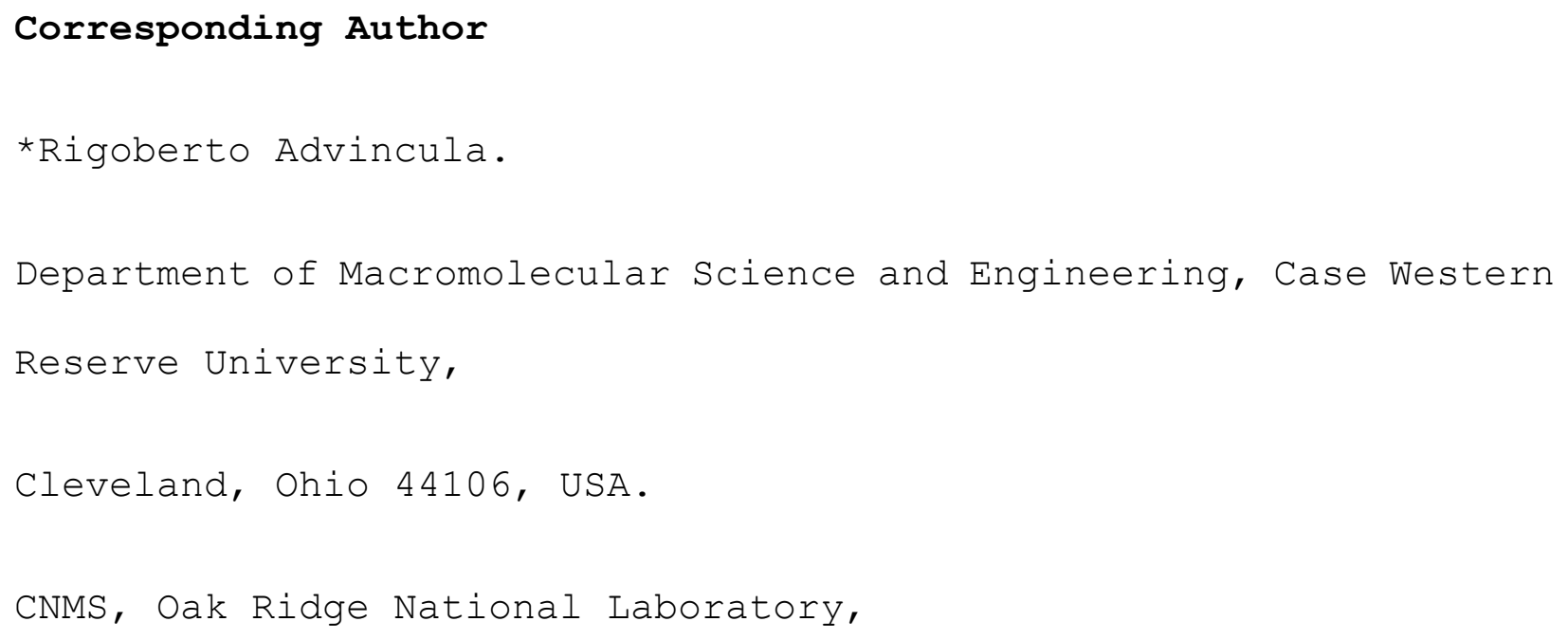


Oak Ridge, Tennessee 37830, USA.

E-mail: rca4lecase.edu

Phone: +1 216-368-4566
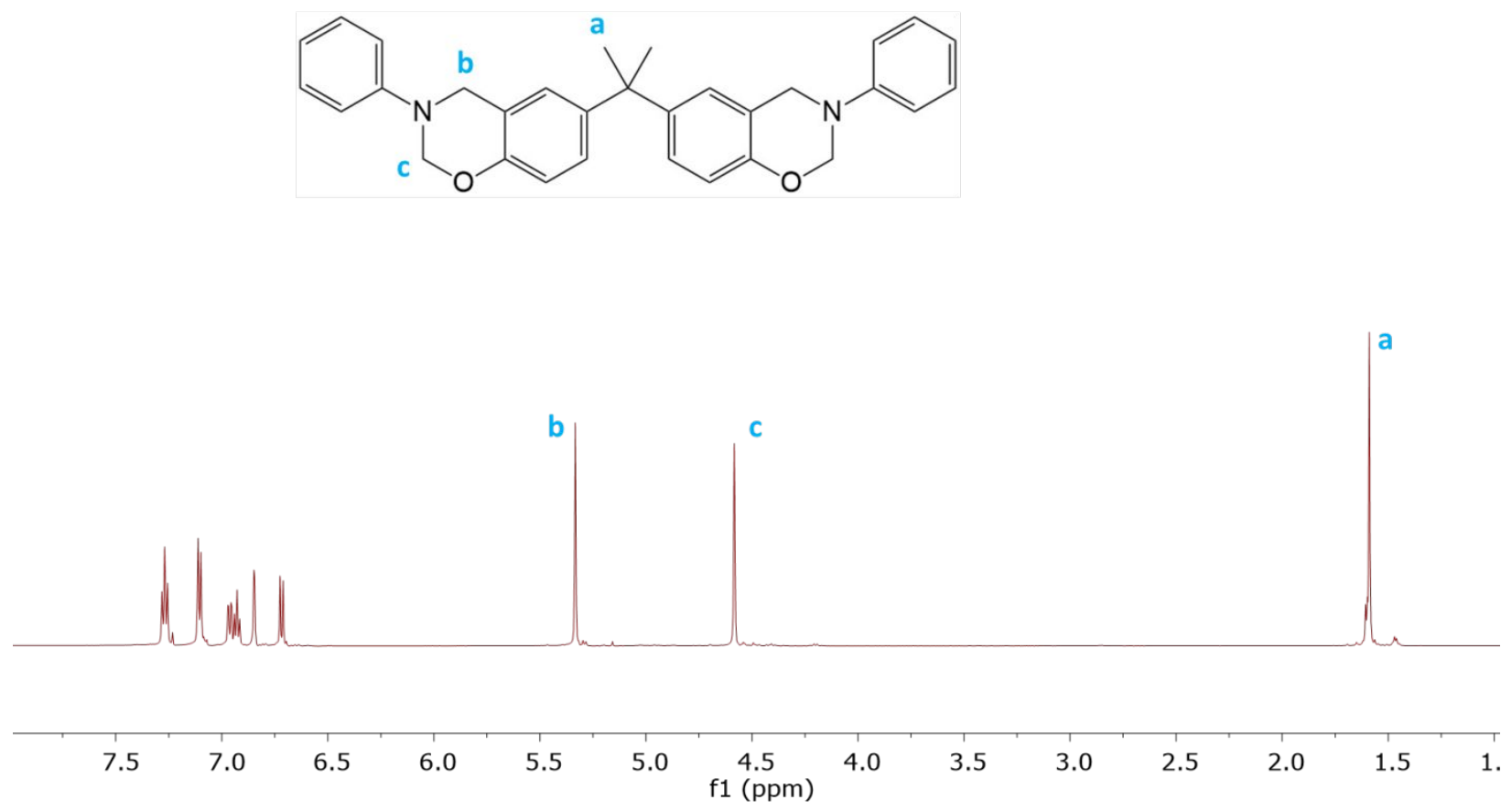

Figure S1. ${ }^{1} \mathrm{H}$ NMR data o synthesized BA-a. 


\begin{tabular}{lc}
\hline Components & $\%$ \\
\hline $\begin{array}{l}\text { Poly[oxy(methyl-1,2-ethanediyl)], a-hydro-w-hydroxy-, ether with 2,2- } \\
\text { bis(hydroxymethyl)-1,3-propanediol (4:1), 2- hydroxy-3-mercaptop }\end{array}$ & $60-100$ \\
N-Aminoethylpiperazine & $5-10$ \\
2,4,6-Tris(dimethylaminomethyl)phenol & $5-10$ \\
Silica, amorphous, fumed & $1-5$ \\
\hline
\end{tabular}

Table S1. Chemical compositions of Loctite Heavy duty hardener. 

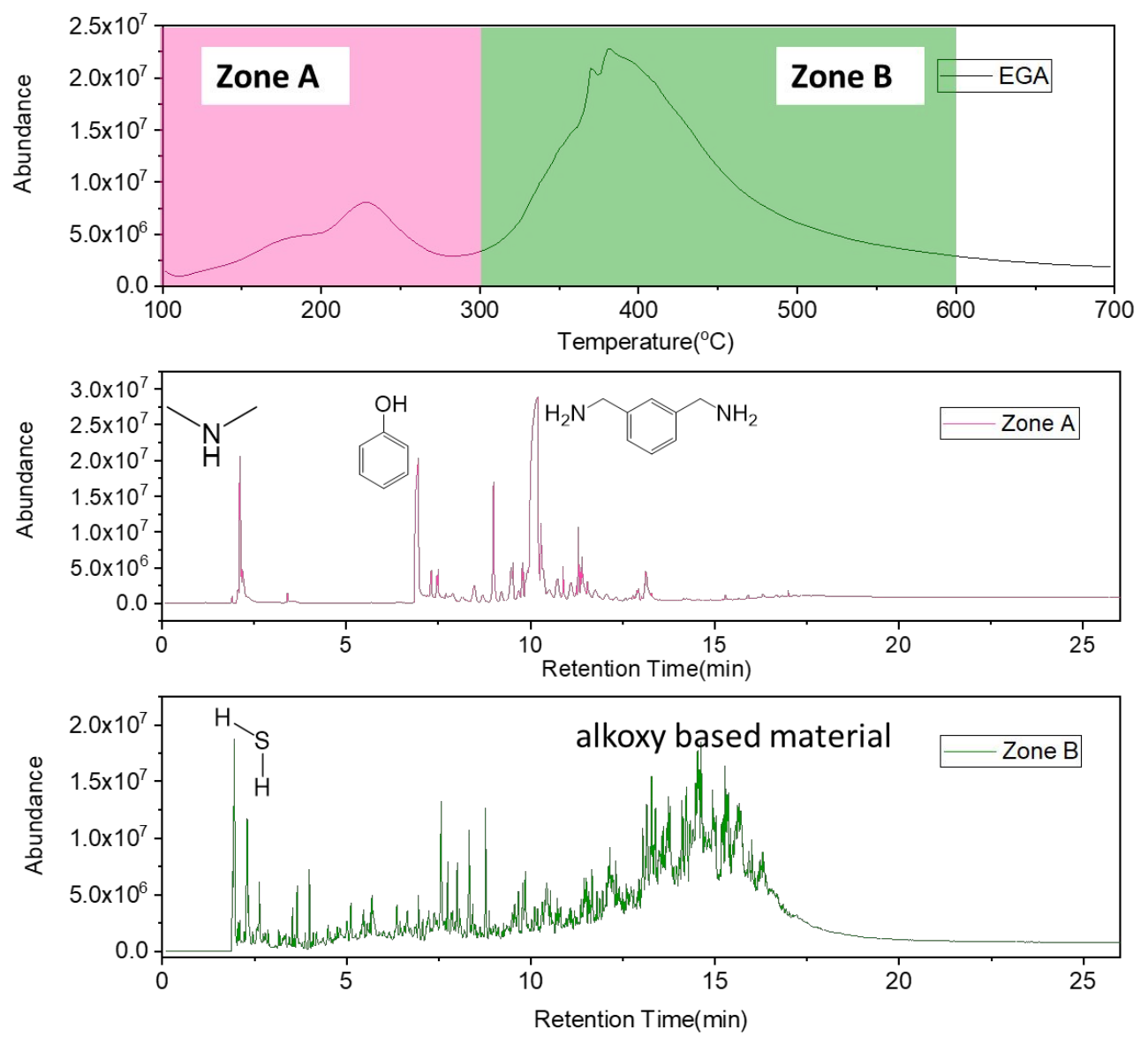

Figure S2. Prolysis-GC/MS data of Loctite Heavy duty hardener.

The Prolysis-GC/MS data shows that the hardener is a mixture of alkoxy-based material, a mercaptop-based material and an m-Phenylenebis(methylamine) based material, which is consistent with the information provided by the manufacturer. 


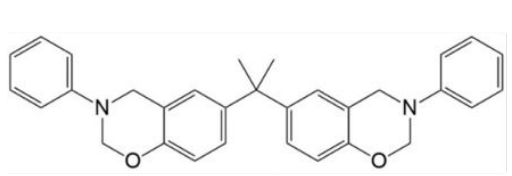

BA-a
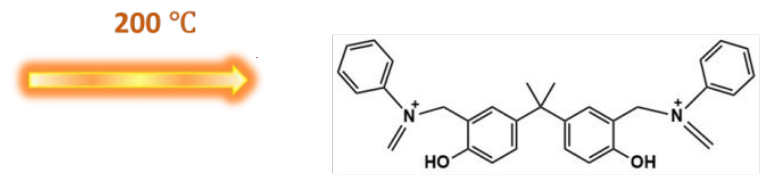

BA-a intermediate
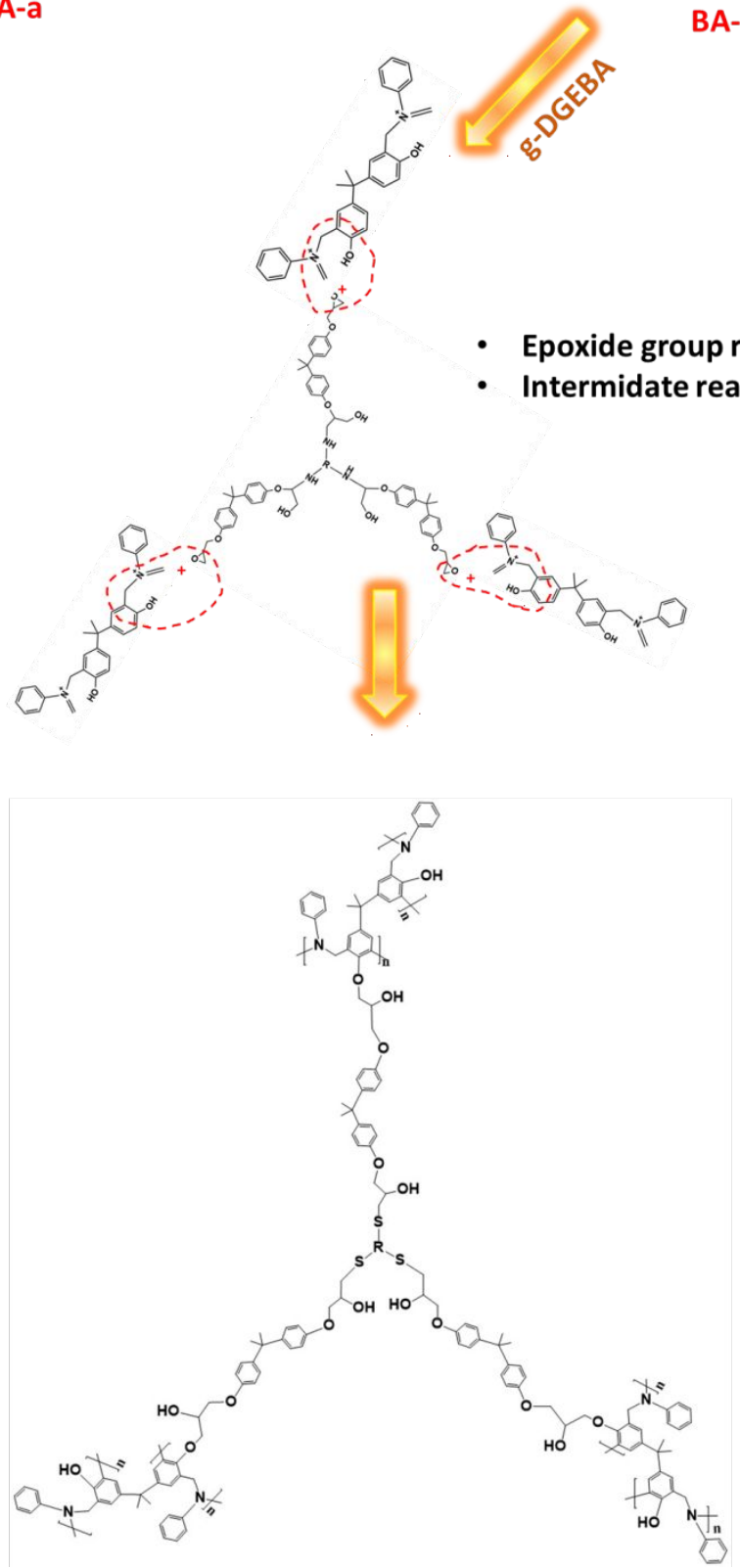

Figure S3. Crosslinking reaction between BA-a and g-DGEBA.

As shown in Figure S3, when heated above $200{ }^{\circ} \mathrm{C}$, oxazine ring will open to genearate a phenol group and a $-\mathrm{N}^{+}=\mathrm{C}$ intermediate. The phenol group will react with the epoxide group in $\mathrm{g}$-DGEBA 
while the $-\mathrm{N}^{+}=\mathrm{C}$ intermediate will react with the phenol ortho position in BA-a, which increases the crosslinking density.
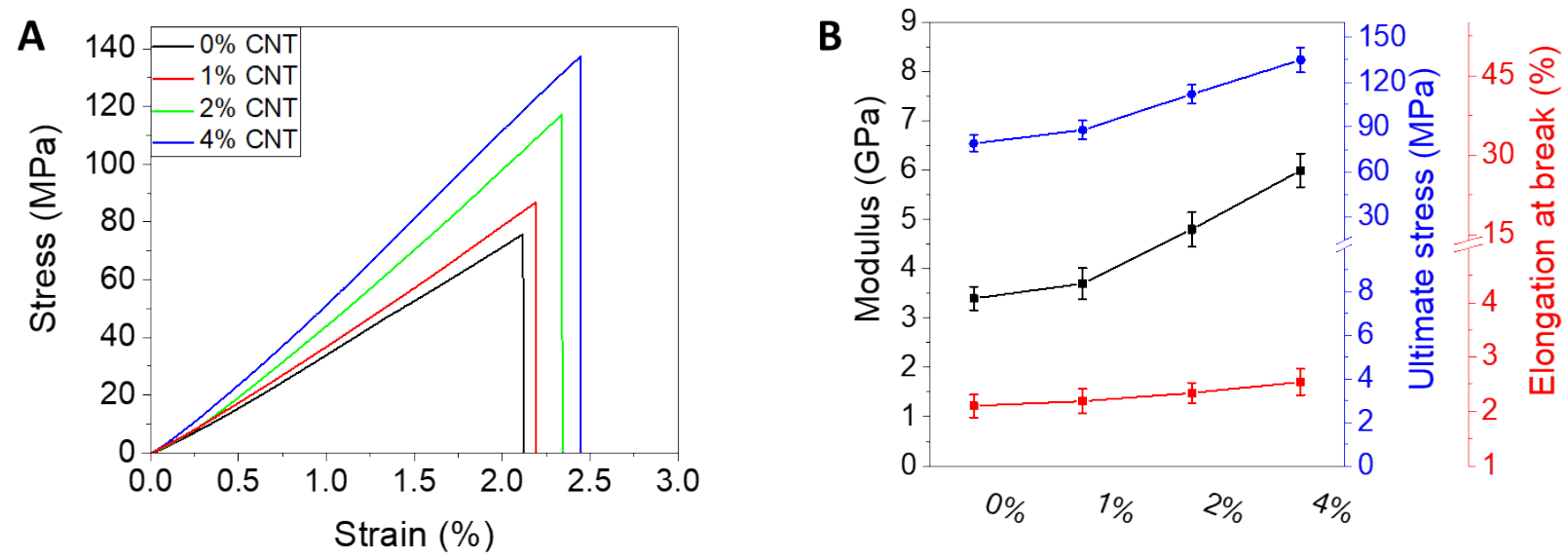

Figure S4. Flexure test of g-DGEBA/BA-a with different loadings of CNT. 

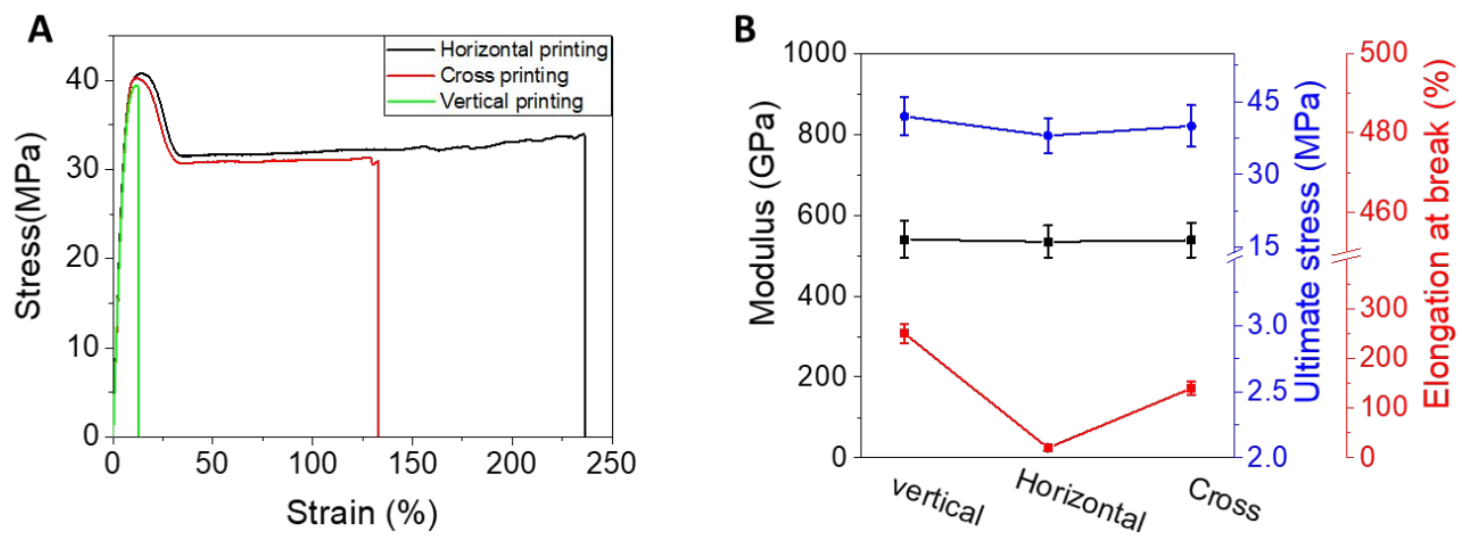

\section{Voids induced by layer delamination}

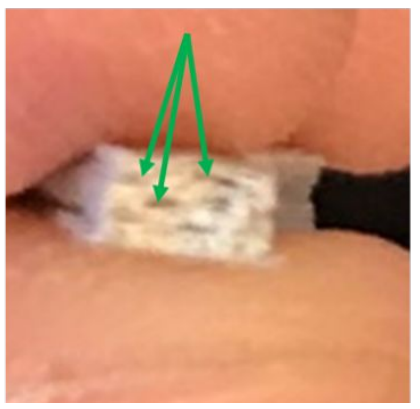

Figure S5. Tensile test of FDM printed Nylon 12 of three printing orientations. A) Stress-strain curves. B) Values of modulus, stress, strain at break. C) Optical images of cross-section of tensile specimen.

\begin{tabular}{cccccc}
\hline Crosslinker & $\operatorname{Tg}\left({ }^{\circ} \mathrm{C}\right)$ & $\begin{array}{c}\text { Storage modulus } \\
(\mathrm{GPa})\end{array}$ & $\begin{array}{c}\text { Char yield } \\
(\%)\end{array}$ & $\begin{array}{c}\text { Maximum } \\
\text { degradation rate } \\
\left(\% /{ }^{\circ} \mathrm{C}\right)\end{array}$ & $\begin{array}{c}\text { Initial degradation } \\
\text { temperature }\left({ }^{\circ} \mathrm{C}\right)\end{array}$ \\
\hline E3140 & 100 & 1.2 & 2.32 & 1.1 & 330 \\
W agent & 130 & 2.1 & 8.02 & 2.1 & 320 \\
BA-a & 178 & 3.6 & 30.3 & 0.5 & 360 \\
\hline
\end{tabular}


Table S2. Summary of thermal properties of g-DGEBA cured by E3140, W agent and BA-a.

\begin{tabular}{|c|c|c|c|}
\hline Properties & Unit & Value & Method of measurement \\
\hline Average diameter & $10^{-9} \mathrm{~m}$ & 9.5 & Transmission Electron Microscopy (TEM) \\
\hline Average length & $\mu \mathrm{m}$ & 1.5 & Transmission Electron Microscopy (TEM) \\
\hline Carbon purity & $\%$ & 90 & Thermogravimetric analysis (TGA) \\
\hline Transition Metal oxide & $\%$ & $<1 \%$ & $\begin{array}{l}\text { Inductively Coupled Plasma Mass } \\
\text { Spectrometry (ICP-MS) }\end{array}$ \\
\hline Amorphous carbon & - & $*$ & $\begin{array}{l}\text { High resolution Transmission Electron } \\
\text { Microscopy (HRTEM) }\end{array}$ \\
\hline Surface Area & $\mathrm{m}^{2} / \mathrm{g}$ & $250-300$ & BET surface area analysis \\
\hline Volume resistivity & $\Omega . \mathrm{cm}$ & $10^{-4}$ & Internal test method (resistivity on powder) \\
\hline
\end{tabular}

Table S3. Physical properties of NC7000 carbon nanotube. 